\title{
МОДЕЛЬ УПРАВЛЕНИЯ СТЕЙКХОЛДЕРАМИ \\ В СДЕЛКАХ СЛИЯНИЙ И ПОГЛОЩЕНИЙ
}

Вашакмадзе T.T. ${ }^{1}$ Мартиросян Э.Г. ${ }^{2}$, Сергеева А.А. ${ }^{3}$

Стратегическое развитие компании и ее стоимость испытывают на себе воздействие со стороны различных групп внешних и внутренних стейкхолдеров. В условиях нарастающей интенсивности процессов корпоративной интеграции и трансформации проявляется потребность менеджеров-практиков в системе управления процессами слияний и поглощений, основанной на стейкхолдерском подходе, а следовательно, высока актуальность разработки специальной метрики для выявления и отслеживания интересов стейкхолдеров в этих сделках. В настоящей работе получила развитие модель управления взаимодействием со стейкхолдерами в сделках слияний и поглощений «SUN Cube» (Martirosyan and Vashakmadze, 2013), показаны механизмы ее использования в достижении синергии при последующей интеграции.

Показателем экономической целесообразности слияния и поглощения является синергетический эффект. А. Дамодаран (Damodaran, 2005) определяет синергию как «дополнительную стоимость, генерируемую путем объединения двух фирм и создания возможностей, которые не были бы доступны этим фирмам, существовавшим независимо друг от друга».

Для оценки синергии в слияниях и поглощениях инвестиционные специалисты прибегают к использованию моделей дисконтированных денежных потоков. Однако, как известно, финансовые коэффициенты являются следствием принятия управленческих решений. Для построения нашей модели оценки синергию рассматривается иначе - через мультипликаторы оценки (price-to-book ratio, отношение рыночной стоимость собственного капитала к балансовой стоимости собственного капитала). Декомпозиция стоимостного мультипликатора показывает, что объединенная компания может достичь синергию по средствам максимизации рентабельности собственного капитала, минимизация рисков и наращивания темпов роста.

Для последующего выявления драйверов роста стоимости компании, используется модель эрцгаммы (Вашакмадзе, 2012). Мы полагаем, что «SUN Cube» может быть применен для анализа каждого из 12 факторов модели эрцгаммы. Менеджерам необходимо определить стейкхолдеров, имеющие непосредственное влияние на каждый фактор, который будет проанализирован по четырем параметрам модели «SUN Cube». Модель «SUN Cube», является диагностическим и аналитическим инструментом, задающим вектор для коррекции коммуникационной стратегии в процессах слияний и поглощений, что позволяет минимизировать риски для синергии и интеграции компаний.

\section{JEL: G34}

Ключевые слова: слияния и поглощения, стейкхолдеры, синергия, интеграция, стоимость компании, ESG

\section{Введение}

Важность управления взаимодействием со стейкхолдерами компании в процессе совершения сделок по слиянию и поглощению, а также при последующей интеграции трудно переоценить. Фундаментальная работа Р. Фримана (Freeman, 1984), сформулировавшая теорию стейкхолдеров, привлекла внимание ученых-теоретиков и практиков к различным вопросам, связанным с «причастными сторонами», заинтересованными в финансовых и иных результатах деятельности организации. Исследователи отмечают, что современная управленческая парадигма основана на принципе создания системы управления стоимостью компании в ин-

1. Старший преподаватель кафедры бизнеса и управленческой стратегии РАНХиГС при Президенте РФ, руководитель фин-модель.ру.

2. Канд. эконом. наук, доцент кафедры бизнеса и управленческой стратегии РАНХиГС при Президенте РФ, коммерческий директор ООО «Грофиллекс».

3. Аспирант кафедры общего и стратегического менеджмента ИБДА РАНХиГС при Президенте РФ. 
тересах групп внутренних и внешних стейкхолдеров (Байбурина и Жуковец, 2009; Санин, 2009; Ивашковская, 2012). Стратегическое развитие компании и ее стоимость определяются не только решениями и интересами менеджмента и собственников, но также испытывают воздействие со стороны персонала компании, акционеров, инвесторов, поставщиков, покупателей и потребителей.

Однако в исследованиях подробно не рассматривался стейкхолдерский подход в контексте сделок слияний и поглощений. В условиях стагнирующей экономики, когда органичный рост компаний все чаще замещается «покупкой роста»- укрупнением бизнеса за счет слияний и поглощений, проявляется потребность бизнесменов-практиков в системе управления процессами слияний и поглощений, основанной на стейкхолдерском подходе.

Обычно интеграция в период после совершения сделок по слиянию и поглощению компаний (PMI, Post Merger Integration) рассматривается как проект, для управления которым существует определенная метрика. Высока актуальность разработки специальной метрики для выявления и отслеживания интересов стейкхолдеров в этих сделках.

Исследователи Дональдсон и Престон (Donaldson and Preston, 1995) заметили, что стейкхолдерская теория создает основу для изучения связей, если таковые прослеживаются, между практикой стейкхолдерского управления и достижением различных целей, соотносящихся с показателями экономической эффективности компании. Ученый Мадхаван (Madhavan, 2005) в своей работе отмечает, что «инициаторы и организаторы процессов слияний и поглощений должны управлять семью группами ожиданий заинтересованных сторон». По его мнению, все стейкхолдеры в равной степени важны, и компания может потерять до $10 \%$ клиентов в случае недооценки их значимости в процессе интеграции.

В нашей предыдущей статье (Martirosyan and Vashakmadze, 2013) мы представили концепцию модели управления взаимодействия со стейкхолдерами в сделках слияний и поглощений, получившей название «SUN Cube». «SUN Cube» позволяет сосредоточиться на ключевых показателях эффективности (KPI) управления различными группами стейкхолдеров. В настоящей работе мы разовьем предложенную нами концепцию и покажем, как она может быть использована в достижении синергии в процессе интеграции после совершения сделки.

\section{Модель оценки синергии}

Вопрос рентабельности сделок слияний и поглощений оказался в центре внимания научного и делового сообщества. В своем исследовании Р. Брунер (Bruner, 2001) изучал выгоду от слияния и поглощения для акционеров как компании-покупателя, так и компании-цели. В качестве шкалы успеха слияний и поглощений автор предложил три категории возможного исхода сделок: сохранение стоимости, создание стоимости или разрушение стоимости компании. Областью создания стоимости становится коммерческая, операционная, сервисная и/ или финансовая синергия.

Показателем экономической целесообразности слияния и поглощения является синергетический эффект, такой как рост доходов или снижение затрат (Houston, James and Ryngaert, 2001). А. Дамодаран (Damodaran, 2005) определяет синергию как «дополнительную стоимость, генерируемую путем объединения двух фирм и создания возможностей, которые не были бы доступны этим фирмам, существовавшим независимо друг от друга».

Объяснять синергию принято через математическое выражение: $1+1=3$. Для оценки синергии в слияниях и поглощениях инвестиционные специалисты прибегают к использованию моделей дисконтированных денежных потоков. Сперва происходит оценка стоимости бизнеса «как она есть». Подобная оценка позволяет определить стоимость компании без изменения операционной, инвестиционной и финансовой политики предприятия. Далее проводится оценка стоимости предприятия с допущениями изменения операционной, инвестиционной, финансовой политики. Разница между этими двумя прогнозными значениями и является теоретической максимальной величиной ожидаемой синергии в денежном исчислении. 
Однако достичь этих показателей в результате слияния и поглощения удается не более чем в $50 \%$ случаев.

Для построения нашей модели оценки рассмотрим синергию иначе - через стоимостные мультипликаторы. С применением таких мультипликаторов оценки, как price-to-book ratio (отношение рыночной стоимость собственного капитала к балансовой стоимости собственного капитала), синергия может быть записана следующим образом:

$\mathrm{P} / \mathrm{B}_{\mathrm{A}}+\mathrm{P} / \mathrm{B}_{\mathrm{B}}<\mathrm{P} / \mathrm{B}_{\mathrm{C}}$

$\mathrm{P} / \mathrm{B}_{\mathrm{A}}$ - мультипликатор price to book компании-покупателя;

$\mathrm{P} / \mathrm{B}_{\mathrm{B}}$ - мультипликатор price to book компании-цели;

$\mathrm{P} / \mathrm{B}_{\mathrm{C}}$ - мультипликатор price to book объединенной компании

Мультипликатор price-to-book может быть выражен через рентабельность и стоимость собственного капитала фирмы, а также темпы роста денежных потоков:

$\mathrm{P} / \mathrm{B}=(\mathrm{ROE}-\mathrm{g}) /(\mathrm{Re}-\mathrm{g})$

Следовательно, представленное выше выражение может трансформироваться:

$\left(\mathrm{ROE}_{\mathrm{A}}-\mathrm{g}_{\mathrm{A}}\right) /\left(\mathrm{Re}_{\mathrm{A}}-\mathrm{g}_{\mathrm{A}}\right)+\left(\mathrm{ROE}_{\mathrm{B}}-\mathrm{g}_{\mathrm{B}}\right) /\left(\mathrm{Re}_{\mathrm{B}}-\mathrm{g}_{\mathrm{B}}\right)<\left(\mathrm{ROE}_{\mathrm{C}}-\mathrm{g}_{\mathrm{C}}\right) /\left(\mathrm{Re}_{\mathrm{C}}-\mathrm{g}_{\mathrm{C}}\right)$

$\mathrm{ROE}$ - рентабельность собственного капитала;

$\mathrm{R}_{\mathrm{e}}$ - стоимость собственного капитала;

$\mathrm{g}$ - темпы роста.

Полученная формула демонстрирует, что объединенная компания может достичь синергии посредством:

- $\quad$ максимизации ROE;

- снижение требуемой доходности на собственный капитал $\mathrm{R}_{\mathrm{e}}$ (минимизация рисков);

- наращивания темпов роста.

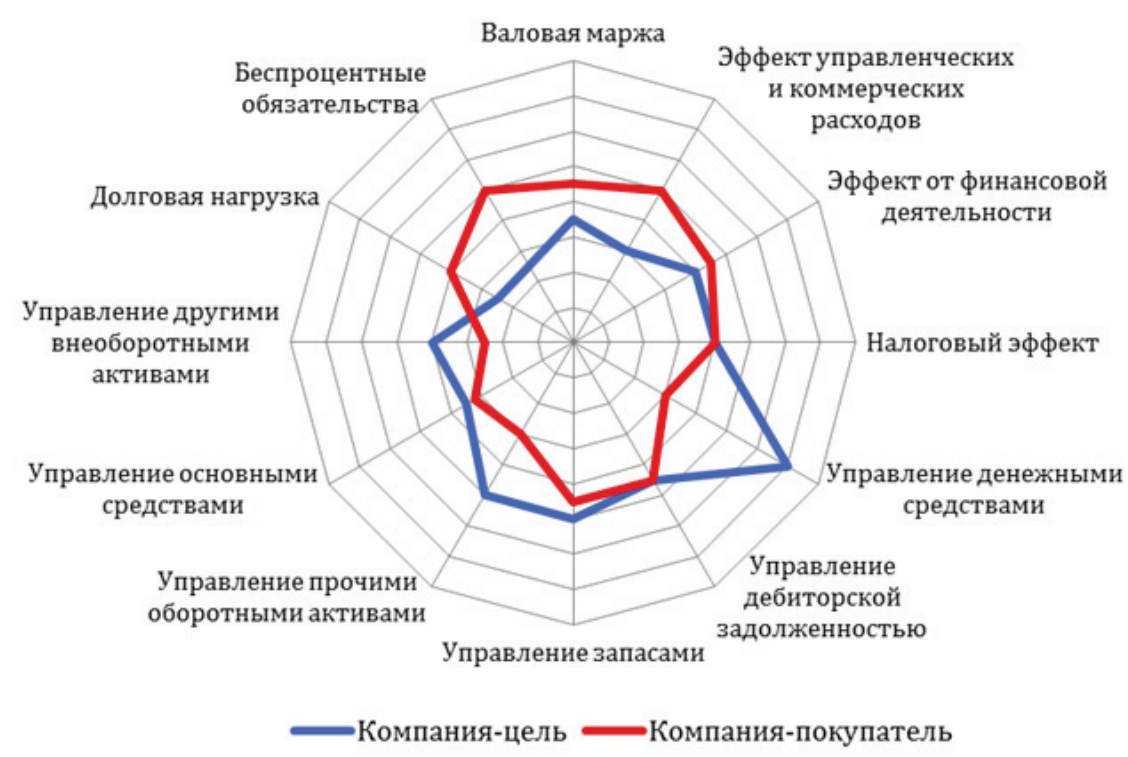

Диаграмма 1. Эригамма

Для последующего анализа и выявления драйверов роста стоимости компании необходимо провести декомпозицию рентабельности собственного капитала (ROE). Вместо традиционной декомпозиции используем модель эрцгаммы (Вашакмадзе, 2012).

Эрцгамма - визуализация двенадцатифакторной модели ROE на лепестковой диаграмме (диаграмма 1). 
Двенадцатифакторная модель декомпозиции ROE:

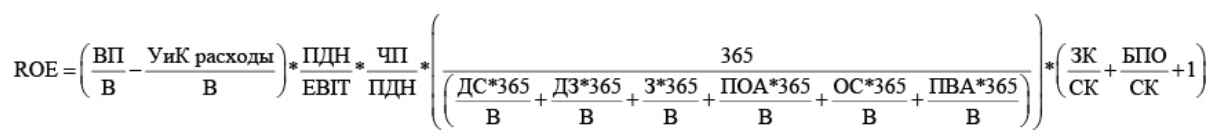

ВП - валовая прибыль,

УиК расходы - управленческие и коммерческие расходы

В - выручка,

EBIT - прибыль до вычета процентов и налогов,

ПДН - прибыль до налогообложения,

ЧП - чистая прибыль.

ДС - денежные средства,

ДЗ - дебиторская задолженность,

3 - запасы,

ПОА - прочие оборотные активы,

ОС - основные средства,

ПВА - прочие внеоборотные активы,

ЗК - заемный капитал, (краткосрочные кредиты и долгосрочные кредиты),

СК - собственный капитал,

БПО - беспроцентные обязательства (в первую очередь это кредиторская задолженность, но также все статьи пассива, кроме собственного капитала, краткосрочных и долгосрочных кредитов).

Использование модели эрцгаммы позволяет:

- определить области достижения синергии;

- дать оценку синергии объединенной компании;

- выявить степень различия компаний и потенциальную возможность к синергии.

\section{Модель управления стейкхолдерами в сделках M\&A - «SUN Cube»}

Целый ряд исследований посвящен стратегиям управления взаимодействием со стейкхолдерами (Savageet et al., 1991; Jawahar and McLaughlin, 2001), а также влиянию стейкхолдеров на решения фирмы (Frooman, 1999).

«Sun Cube» является новой моделью, которая может быть использована в управлении сделками по слиянию и поглощению для анализа взаимодействия компании со стейкхолдерами через призму четырех параметров: степень вовлеченности / перспектива участия (Run Rate), уровень определенности / перспектива прозрачности (Transparency Rate), перспектива мультипликативного эффекта (Multiplication Rate), перспектива управленческого перехода на новый этап бизнес-философии (Transmission Rate).

Каждый критерий оценивается по нескольким уровням стейкхолдеров.

В нашей классификации выделено три уровня стейкхолдеров. Первый и второй уровни представлены ключевыми стейкхолдерами, которые оказывают или могут оказать непосредственное влияние на будущие денежные потоки компании. Третий условно выделенный уровень - «удаленные» стейкхолдеры, которые косвенно влияют на функционирование бизнеса. 


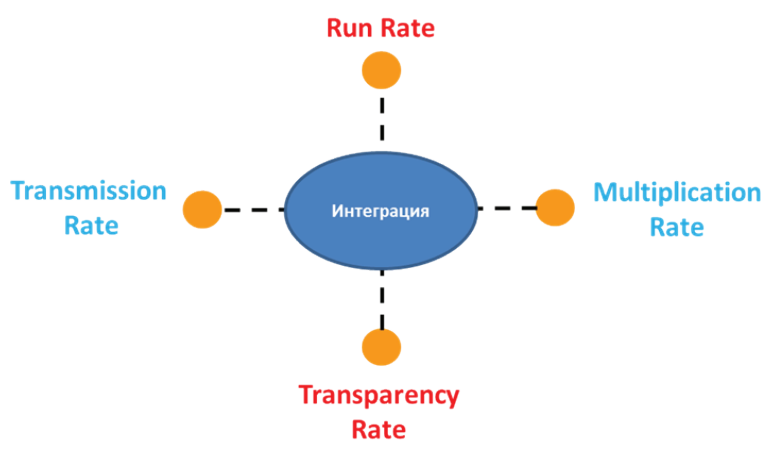

Диаграмма 2. Модель «SUN Cube»

Уровни стейкхолдеров:

- 1-й уровень стейкхолдеров (SH1) - акционеры, топ-менеджмент и персонал компании;

- 2-й уровень стейкхолдеров (SH2) - клиенты, поставщики и банки;

- $\quad$ 3-й уровень стейкхолдеров (SH3) - прочие заинтересованные стороны, в том числе специфические по отношению к среде действия компании.

В зависимости от ситуации внешние стейкхолдеры могут переходить с третьего на второй уровень и наоборот.

\section{Описание параметров модели «SUN Cube»}

Run rate - степень вовлеченности стейкхолдеров в корпоративную трансформацию. Этот КРI введен для определения возможности и готовности стейкхолдеров участвовать в процессах, сопряженных со сделкой по слиянию и поглощению и последующей интеграцией. Известно, что большинство сделок M\&A страдают от так называемой «корпоративной аллергии»явления, при котором в ходе интеграции две или более бизнес-структуры не могут успешно объединиться и достичь синергетического эффекта из-за несовместимости, существенного расхождения в интересах стейкхолдеров. Это приводит к отторжению структур, и цели синергий проваливаются.

Целевые и фактические значения выставляются по следующей шкале вовлеченности стейкхолдеров в сделку:

0 - не вовлечены;

1 - поставлены в известность / информированы о совершении сделки;

2 - активно участвуют в рабочих группах по интеграции;

3 - вовлечены на стадии принятия решения.

Анализируя значение этого параметра, необходимо дать ответ на вопрос о том, какая степень вовлеченности стейкхолдеров в сделку необходима для достижения синергетического эффекта.

Transparncy rate - степень прозрачности, определенности будущего для стейкхолдеров после интеграции. Без четкого видения того, что произойдет со всеми заинтересованными сторонами после сделки, представления о том, как изменится их положение, невозможно провести ни успешное слияние и поглощение, ни последующую интеграцию. Перед совершением сделки рекомендуется сформировать карту будущего для всех заинтересованных сторон, в которой будет указана следующая информация:

- Величина «стейка» в компании (масштаб бизнеса, доходы), который сохранит за собой стейкхолдер после интеграции. Когда сделка по слиянию и поглощению инициируется и рассматривается в качестве инструмента роста стоимости бизнеса, она должна быть максимально полезной для стейкхолдеров и не ухудшать их положения.

- $\quad$ Стратегический и оперативный план на период от 3 до 5 лет с финансовыми и социальными ключевыми показателями эффективности. 
Целевые и фактические значения ранжируются по следующей шкале степени определенности будущего для каждого стейкхолдера после сделки:

0 - определено, непрозрачно;

1 - определено / прозрачно в краткосрочном периоде, до 6 месяцев;

2 - определено / прозрачно в среднесрочном периоде, от 6 месяцев до 1 года;

3 - полная определенность / прозрачность в долгосрочном периоде, более 1 года.

Multiplication rate - показатель, отражающий возможность стейкхолдеров получить от сделки мультипликативные эффекты в нерелевантных бизнесах. Работая в отрасли, в которой сосредоточены ключевые компетенции, компания неизбежно влияет на смежные отрасли, обслуживающие бизнес или инвестирующие в него. Таким образом, при слияниях и поглощениях необходимо понять, какие дополнительные преимущества создаст сделка и последующая интеграция для стейкхолдеров из смежных отраслей. При увеличении стоимости для наших стейкхолдеров необходимо учитывать сопряженное с этим увеличение их стоимости в смежных бизнесах.

KPI позволяет генеральному директору, совершающему сделку и проводящему интеграцию, проанализировать возможность стейкхолдеров максимизировать стоимость после сделки в нерелевантных областях. Рассмотрение мультипликативного эффекта может оказаться полезным для выстраивания коммуникационной стратегии.

Целевые и фактические значения мультипликативного эффекта:

0 - мультипликативный эффект отсутствует;

1 - мультипликативный эффект существует.

Transmission rate отражает этап, на котором находится бизнес-философия внутренних стейкхолдеров, участвующих в сделке по слиянию и поглощению, а также возможность перехода на уровень выше в результате сделки. Можно выделить четыре стадии эволюции философии корпоративного управления (диаграмма 2):

- фокус на позитивный денежный поток;

- фокус на позитивную операционную прибыль или рентабельность по EBITDA;

- фокус на создание стоимости для стейкхолдеров;

- $\quad$ фокус на социальную ответственность, ESG (экологические, социальные и управленческие аспекты).

Опираясь на данный KPI, топ-менеджмент компании может составить представление о совместимости философий управления, которых придерживаются внутренние стейкхолдеры интегрируемых компаний, а также определить, каковы основные драйверы слияния и поглощения. Взгляд на данный показатель позволяет руководству понять общие приоритеты и подходы стейкхолдеров, что поможет избежать многих проблем, связанных с интеграцией. Этот KPI может предотвратить сделку по интеграции бизнесов, кардинально отличающихся с точки зрения философии и подходов. Полагаем, что родственность философий объединяемых компаний влияет на успех сделок слияний и поглощений и на вероятность достижения при этом синергии.

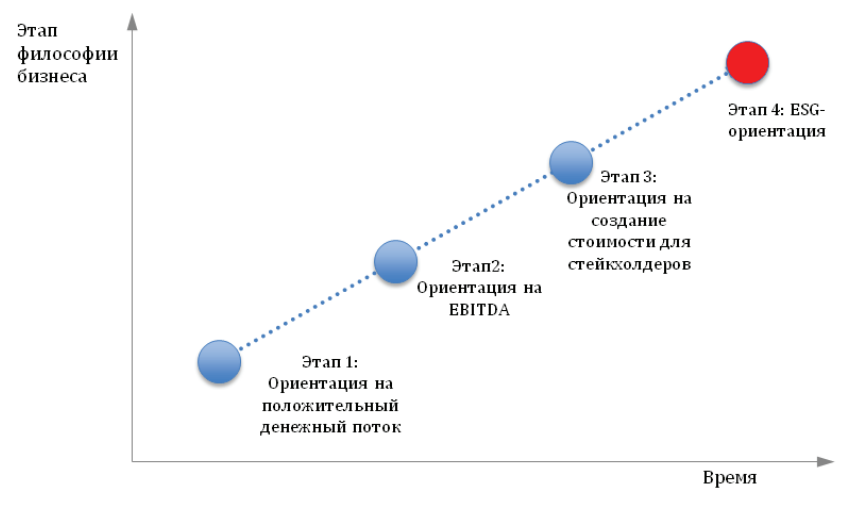


Четвертый этап эволюции подхода к управлению компанией - акцент на ESG - требует принципиально другой управленческой философии развития бизнеса.

Для успеха будущей интеграции стейкхолдеры должны находиться на одной и той же стадии, разделять одну философию. Это имеет критическое значение для создания стоимости и формирования надежной коммуникационной основы. Чем больше точек соприкосновения в философии, подходах, приоритетах стейкхолдеров, тем больше вероятность будущей успешной интеграции. Крайне трудно осуществить успешную интеграцию, если одни стейкхолдеры находятся на стадии ESG, а для других главным по-прежнему остается положительный денежный поток. Общее понимание и философия в бизнес-модели приносят положительные результаты в виде успешной интеграции.

Transmission rate - единственный показатель, который анализируется только для первой группы стейкхолдеров. Для учета этого показателя применяется метод оценки «360 градусов». Целевые и фактические значения проранжированы согласно этапам эволюции корпоративной философии:

0 - ориентация на положительный денежный поток;

1 - ориентация на EBITDA;

2 - ориентации на рыночную капитализацию;

3 - ESG-ориентация (максимизация благосостояния акционеров через максимизацию выгоды для стейкхолдеров).

Таким образом, модель «SUN Cube» - это система оценки потенциальной синергии до, в процессе и после сделок слияний и поглощений компаний в рамках стейкхолдерского подхода, представленная в разрезе четырех параметров и дающая ответ на четыре ключевых вопроса:

1. Какая степень вовлеченности стейкхолдеров в сделке необходима для достижения синергетических эффектов?

2. Насколько определено будущее для каждого стейкхолдера после сделки?

3. Какие мультипликативные эффекты получают стейкхолдеры от сделки?

4. На какой этап философии управления компанией необходимо переводить внутренних стейкхолдеров?

Оценочный лист, составленный по системе показателей модели «SUN Cube», приведен в таблице 1.

Оценочный лист по системе показателей модели «SUN Cube»

\begin{tabular}{|c|c|c|c|c|c|}
\hline $\begin{array}{c}\text { Критерии / } \\
\text { стейкхолдеры }\end{array}$ & $\begin{array}{c}\text { Целевое } \\
\text { значение }\end{array}$ & $\begin{array}{c}\text { Фактическое } \\
\text { значение }\end{array}$ & $\%$ & Комментарий & $\begin{array}{c}\text { Меры по } \\
\text { оптимизации }\end{array}$ \\
\hline Run rate & 9 & & & & \\
\hline SH1 & 3 & & & & \\
\hline SH2 & 3 & & & & \\
\hline SH3 & 3 & & & & \\
\hline Transparency rate & 9 & & & & \\
\hline SH1 & 3 & & & & \\
\hline SH2 & 3 & & & & \\
\hline SH3 & 3 & & & & \\
\hline Multiplication rate & 3 & & & & \\
\hline SH1 & 1 & & & & \\
\hline SH2 & 1 & & & & \\
\hline SH3 & 1 & & & & \\
\hline Transmission rate & 9 & & & & \\
\hline
\end{tabular}




\begin{tabular}{|c|c|l|l|l|l|}
\hline Акционеры & 3 & & & & \\
\hline Топ-менеджмент & 3 & & & & \\
\hline Персонал & 3 & & & & \\
\hline ИТОГО: & 30 & & & & \\
\hline
\end{tabular}

Таблица соотносит целевые и фактические значения, полученные по итогам анкетирования и опросов. Каждый критерий дифференцируется по уровням стейкхолдеров. Далее в процентах рассчитывается отклонение фактического значения от целевого, предлагаются меры по оптимизации каждого из показателей. Максимальная сумма показателей составляет 30, минимальное значение равно 0.

Целевые и фактические значения могут быть графически изображены для каждого критерия, как это показано ниже (диаграмма 4).

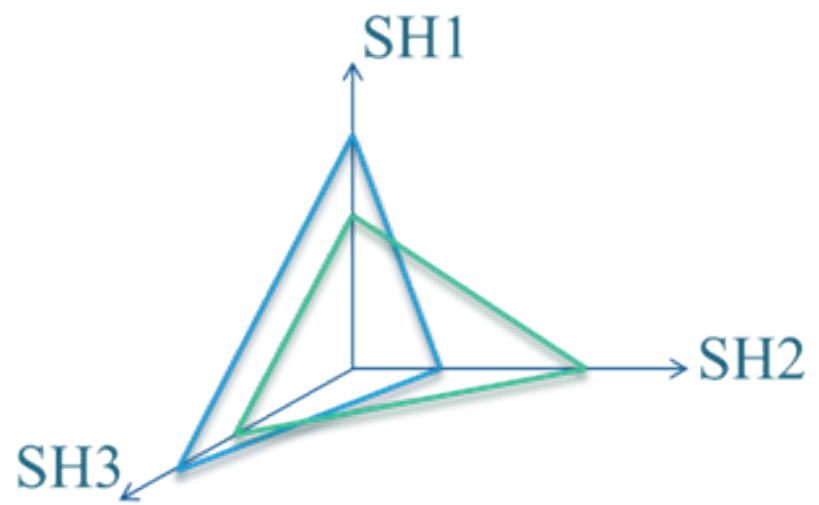

Диаграмма 4. Целевые и фактические значения параметра модели «SUN Cube»

Важно отметить, что горизонтальные критерии модели «SUN Cube» (Multiplication Rate и Transmission Rate) дают пассивную оценку, а вертикальные (Run Rate и Transparency Rate) активную. По нашему мнению, чем выше фактическое значение, полученное по метрике, тем более управляемым является процесс слияний и поглощений, тем больший синергетический эффект может быть получен. Агрегированное значение отражает вовлеченность стейкхолдеров в сделку и соотносится с возможностью достижения синергии в результате слияний и поглощений. Низкая суммарная оценка является индикатором существования рисков недостижения синергии и медленной интеграции.

Сегодня такие явления, как аннигиляция и эрозия стоимости в рамках интеграционных процессов на глобальном рынке слияний и поглощений, сформировали восходящий тренд. Неэффективная, медленная - «тлеющая» - интеграция все чаще становится предпосылкой для реверсивных процессов, обратных поглощений, при которых покупатель и цель меняются местами.

Модель «SUN Cube» является диагностическим и аналитическим инструментом, задающим вектор для коррекции коммуникационной стратегии в процессах слияний и поглощений, что позволяет минимизировать риски для синергии и интеграции компаний.

\section{Заключение}

В настоящей статье получила развитие ранее предложенная нами концепция «SUN Cube», рассмотрены области захвата синергии в период корпоративной интеграции до, в процессе и после совершения сделок по слиянию и поглощению. Предложена новая модель оценки синергии (эрцгамма), которая может применяться вместе с моделью «SUN Cube».

Как известно, финансовые коэффициенты являются следствием принятия управленческих решений. Модель эрцгаммы - это первый шаг. На решения, принимаемые в процессах слияний и поглощений, могут оказывать прямое или косвенное воздействие стейкхолдеры компании. Мы полагаем, что «SUN Cube» может быть применен для анализа каждого из 12 факторов модели эрцгаммы. Менеджерам необходимо определить заинтересованные стороны, 
имеющие непосредственное влияние на каждый фактор, который будет проанализирован по четырем параметрам модели «SUN Cube».

Наша следующая статья будет посвящена подробному описанию методологии, комбинирующей эрцгамму и «SUN Cube» для того, чтобы представить целостную систему управления взаимодействием со стейкхолдерами в сделках слияний и поглощений компаний

\section{Список литературы}

1. Байбурина Э.Р., Жуковец О.С. Концепция анализа сетевого капитала как драйвера стоимости компании // Корпоративные финансы. 2009.

2. Вашакмадзе Т., Сравнительный анализ бизнес-моделей компаний // Экономика и жизнь, № 45/9461 от 16 ноября 2012 г.

3. Ивашковская И.В. Стейкхолдерский подход к управлению, ориентированному на приращение стоимости компании // Корпоративные финансы. 2012. № 1(21). С.14-23.

4. Санин В.В. Баланс и конфликт интересов стейкхолдеров в стратегических и бизнеспланах компании // Корпоративные финансы. 2009. № 2 (10). С. 112-132.

5. Bruner, R., (2002). Does M\&A pay? A survey for the decision-maker. Journal of Applied Finance, 12 (2002) 48-60.

6. Damodaran, A. (2005), The Value of Synergy. Available at SSRN: http://ssrn.com/abstract $=841486$ or http://dx.doi.org/10.2139/ssrn.841486.

7. Donaldson, T., and Preston, L.E. (1995), The stakeholder theory of the corporation: Concepts, evidence, and implications, Academy of Management Review, 20 (1995) 65-91.

8. Freeman, R.E. (1984), Strategic Management: A stakeholder approach. Boston: Pitman.

9. Jawahar, I.M., and McLaughlin, G.L. (2001), Toward a descriptive stakeholder theory: An organizational life cycle approach, Academy of Management Review, 26 (2001) 397-414.

10. Houston, J., James, C., Ryngaert, M., (2001), Where Do Merger Gains Come From? Bank Mergers From the Perspective of Insiders and Outsiders, Journal of Financial Economics, 2-3(60) (2001) 285-331.

11. Madhavan, R. (2005), Managing M\&A Strategically: From «Plug and Pray» To «Plug and Play». Ravi Madhavan's A\&D Blog available at: http://strategyscape.typepad.com/PlugPlay. pdf.

12. Martirosyan, E., Vashakmadze, T. (2013), Introducing Stakeholder Based Frameworks for Post-Merger Integration Success. Global Business Conference Proceedings, p. 169-175, ISSN 1848-2252. Available at SSRN: http://ssrn.com/abstract=2211646.

13. Savage, G.T., Nix, T.W., Whitehead, C.J., and Blair, J.D. (1991), Strategies for assessing and managing stakeholders, Academy of Management Executive, 5 (1991) 61-75. 
Vashakmadze Teimuraz,

Senior lecturer, department of business and managerial strategy; The Russian Presidential Academy of National Economy and Public Administration; Director, Fin-mofel.ru

Martirosyan Emil,

Associate Professor;Institute of Business Studies (IBSMoscow) within the Russian Presidential Academy of National Economy and Public Administration; Chief Commercial Officer, LLC «Grosfilex»

Sergeeva Anastasia,

Post-graduate student, department of general and strategic management, The Russian Presidential Academy of National Economy and Public Administration

\begin{abstract}
Absract
Strategic development and value of the company are strongly influenced by different groups of internal and external stakeholders such as shareholders, top-management, personnel, clients, suppliers, banks and others. Considering the growing M\&A activity, there is a high need for a stakeholder based management system and metrics to trace the interests of all stakeholders that can be used by practitioners. This paper develops a conceptual framework of the stakeholder management model for M\&A deals, called the SUN Cube (Martirosyan and Vashakmadze, 2013) and shows how the SUN Cube framework can be used in capturing synergies during the post-merger integration process.

Aswath Damodaran (Damodaran, 2005) defines synergy as "the additional value that is generated by combining two firms, creating opportunities that would not have been available to these firms operating independently." Usually, investment professionals use cash flow models for the valuation of synergy in mergers and acquisitions. In our paper we employ valuation multiples such as the price to book ratio for defining the synergy. From this model we can state that the combined (united) company can achieve synergy via maximization of return on equity (ROE), risk reduction and growth maximization.

To identify company value drivers, we perform ROE decomposition approaching the ertsgamma model (Vashakmadze, 2012). We suggest that the SUN Cube model can be used for each 12 factors. Managers will need to identify the stakeholders that will have a direct impact on each factor, and each factor will be analyzed via 4 perspectives of the SUN cube: Run Rate, Transparency Rate, Multiplication Rate, Transmission Rate. The SUN Cube scorecard shows target and actual values for each perspective, and perspective is decomposed by three stakeholder levels. We believe that the higher the actual value is, the more controllable and manageable the synergy effects are.
\end{abstract}

JEL: G34

Key words: mergers and acquisitions, stakeholders, synergy, integration, company value, ESG.

\title{
References
}

1. Baiburina E.R., Zhukovets O.S. Kontseptsiia analiza setevogo kapitala kak draivera stoimosti kompanii [Concept of analysis of network capital as a corporate value driver]. Korporativnye finansy [Corporate finance], 2009.

2. Bruner R. Does M\&A pay? A survey for the decision-maker. Journal of Applied Finance, 2002, 12, pp. 48-60. 
3. Damodaran A. The Value of Synergy, 2005. Available at SSRN: http://ssrn.com/abstract $=841486$ or http://dx.doi.org/10.2139/ssrn. 841486 .

4. Donaldson T., Preston L.E. The stakeholder theory of the corporation: Concepts, evidence, and implications. Academy of Management Review, 1995, 20, pp. 65-91.

5. Freeman R.E. Strategic Management: A stakeholder approach. Boston: Pitman, 1984.

6. Houston J., James C., Ryngaert M. Where do merger gains come from? Bank mergers from the perspective of insiders and outsiders. Journal of Financial Economics, 2001, 2-3(60), pp. $285-331$.

7. Ivashkovskaia I.V. Steikkholderskii podkhod $\mathrm{k}$ upravleniiu, orientirovannomu na prirashchenie stoimosti kompanii [Stakeholder approach to value based management]. Korporativnye finansy [Corporate finance], 2012, № 1(21), pp.14-23.

8. Jawahar I.M., McLaughlin G.L. Toward a descriptive stakeholder theory: An organizational life cycle approach. Academy of Management Review, 2001, 26, pp. 397-414.

9. Madhavan R. Managing M\&A strategically: From «plug and pray» to «plug and play». Ravi Madhavan's A\&D Blog, 2005. Available at: http://strategyscape.typepad.com/PlugPlay.pdf.

10. Martirosyan E., Vashakmadze T. Introducing stakeholder based frameworks for post-merger integration success. Global Business Conference Proceedings, 2013, p. 169-175. ISSN 1848-2252. Available at SSRN: http://ssrn.com/abstract=2211646.

11. Sanin V.V. Balans i konflikt interesov steikkholderov v strategicheskikh i biznes-planakh kompanii [Balance and conflict of stakeholder interests in strategic and business plans of a company]. Korporativnye finansy [Corporate finance], 2009, № 2 (10), pp. 112-132.

12. Savage G.T., Nix T.W., Whitehead C.J., Blair, J.D. Strategies for assessing and managing stakeholders. Academy of Management Executive, 1991, 5, pp. 61-75.

13. Vashakmadze T. Sravnitel'nyi analiz biznes-modelei kompanii [Comparative analysis of corporate business models]. Ekonomika i zhizn' [Economics and life], 16 November 2012, № 45/9461. 